\title{
Acute Hyponatremia Resulting from Duloxetine-induced Syndrome of Inappropriate Antidiuretic Hormone Secretion
}

\author{
Kosuke Yoshida, Yoko Aburakawa, Yasuhiro Suzuki, Kenji Kuroda and Takashi Kimura
}

\begin{abstract}
:
A 77-year-old woman who had taken a single oral dose of duloxetine subsequently developed a headache and nausea. On the first day, her serum sodium level was $135 \mathrm{mEq} / \mathrm{L}$. She became confused on the third day. Her serum sodium level was $119 \mathrm{mEq} / \mathrm{L}$ and her antidiuretic hormone level was $1.9 \mathrm{IU}$. We diagnosed her with acute hyponatremia from duloxetine-induced syndrome of inappropriate antidiuretic hormone secretion (SIADH). This case suggests that we must not rule out SIADH on the basis of normal serum sodium levels when a patient who has started serotonin-norepinephrine reuptake inhibitor (SNRI) treatment presents with symptoms similar to hyponatremia.
\end{abstract}

Key words: hyponatremia, syndrome of inappropriate antidiuretic hormone, duloxetine, serotoninnorepinephrine reuptake inhibitors

(Intern Med 58: 1939-1942, 2019)

(DOI: 10.2169/internalmedicine.2346-18)

\section{Introduction}

Hyponatremia is defined as a plasma sodium concentration of $<135 \mathrm{mEq} / \mathrm{L}$ and is frequently observed in clinical practice. It can cause nausea, headaches, changes in mental status, seizures, and loss of consciousness. However, the progression of hyponatremia from the acute to the chronic phase is variable. Selective serotonin reuptake inhibitors (SSRIs) and serotonin-norepinephrine reuptake inhibitors (SNRIs) are therapeutic medications for depression and are used in elderly patients worldwide (1). However, SSRIs and SNRIs are known to cause hyponatremia as a secondary effect of the syndrome of inappropriate antidiuretic hormone secretion (SIADH). Although all antidepressants, with the exception of mianserin, are associated with a risk of hyponatremia, duloxetine is associated with a relatively low degree of risk (2).

We herein describe the case of a patient who presented with acute progressive symptoms of hyponatremia caused by SIADH following a single dose of duloxetine and who in- itially showed normal serum sodium levels.

\section{Case Report}

A 77-year-old woman with a history of deep vein thrombosis, hypertension, hyperlipidemia, and anxiety presented with headaches and nausea. Her daily medications prior to admission included warfarin $(3.5 \mathrm{mg})$, rosuvastatin $(2.5 \mathrm{mg})$, telmisartan $(40 \mathrm{mg})$, famotidine $(20 \mathrm{mg})$, benidipine $(4 \mathrm{mg})$, and zolpidem $(5 \mathrm{mg})$. This medication was not changed. In addition, she was prescribed ethyl loflazepate by her psychiatrist. She had not consumed alcohol for the past 10 years. The day before her presentation, her psychiatrist prescribed her duloxetine and discontinued ethyl loflazepate to prevent worsening anxiety. She took a single oral dose of duloxetine in the morning, after which she developed a headache and nausea. She subsequently visited her physician's hospital. At the time her systolic blood pressure was $170 \mathrm{mmHg}$, and the findings of a laboratory examination were mostly normal, including a serum sodium level of 135 $\mathrm{mEq} / \mathrm{L}$. She treated with an orally administered calcium 
Table. Results of Laboratory Examinations on Admission.

\begin{tabular}{|c|c|c|}
\hline \multicolumn{3}{|l|}{ Hematology } \\
\hline & WBC & $11,300 / \mu \mathrm{L}$ \\
\hline & $\mathrm{RBC}$ & $439 \times 10^{4} / \mu \mathrm{L}$ \\
\hline & $\mathrm{Hb}$ & $13.3 \mathrm{~g} / \mathrm{dL}$ \\
\hline & $\mathrm{Ht}$ & $38.5 \%$ \\
\hline & Plt & $7.8 \times 10^{4} / \mu \mathrm{L}$ \\
\hline \multicolumn{3}{|l|}{ Biochemistry } \\
\hline & $\mathrm{TP}$ & $7.1 \mathrm{~g} / \mathrm{dL}$ \\
\hline & Alb & $4.2 \mathrm{~g} / \mathrm{dL}$ \\
\hline & T-bil & $1.13 \mathrm{mg} / \mathrm{dL}$ \\
\hline & AST & $59 \mathrm{U} / \mathrm{L}$ \\
\hline & ALT & $26 \mathrm{U} / \mathrm{L}$ \\
\hline & LDH & $341 \mathrm{U} / \mathrm{L}$ \\
\hline & ALP & $145 \mathrm{U} / \mathrm{L}$ \\
\hline & GGT & $15 \mathrm{U} / \mathrm{L}$ \\
\hline & BUN & $7.3 \mathrm{mg} / \mathrm{dL}$ \\
\hline & Cre & $0.37 \mathrm{mg} / \mathrm{dL}$ \\
\hline & $\mathrm{Na}$ & $119 \mathrm{mEq} / \mathrm{L}$ \\
\hline & $\mathrm{K}$ & $3.6 \mathrm{mEq} / \mathrm{L}$ \\
\hline & $\mathrm{Cl}$ & $87 \mathrm{mEq} / \mathrm{L}$ \\
\hline & FPG & $126 \mathrm{mg} / \mathrm{dL}$ \\
\hline & $\mathrm{CK}$ & $1,987 \mathrm{U} / \mathrm{L}$ \\
\hline & CK-MB & $33 \mathrm{U} / \mathrm{L}$ \\
\hline & Serum osmolality & $260 \mathrm{mOsm} / \mathrm{kg}$ \\
\hline \multicolumn{3}{|l|}{ Serology } \\
\hline & CRP & $0.02 \mathrm{mg} / \mathrm{dL}$ \\
\hline \multicolumn{3}{|l|}{ Coagulation } \\
\hline & $\mathrm{PT} \%$ & $22.5 \%$ \\
\hline & PT-INR & 2.55 \\
\hline & APTT & $38.1 \mathrm{~s}$ \\
\hline \multicolumn{3}{|l|}{ Endocrine } \\
\hline & TSH & $0.53 \mu \mathrm{IU} / \mathrm{L}$ \\
\hline & FT3 & $2.21 \mathrm{pg} / \mathrm{mL}$ \\
\hline & FT4 & $1.380 \mathrm{ng} / \mathrm{dL}$ \\
\hline & Cortisol & $27.8 \mu \mathrm{g} / \mathrm{dL}$ \\
\hline & $\mathrm{ADH}$ & $1.9 \mathrm{pg} / \mathrm{mL}$ \\
\hline \multicolumn{3}{|l|}{ Urine } \\
\hline & $\mathrm{Na}$ & $187 \mathrm{mEq} / \mathrm{L}$ \\
\hline & $\mathrm{K}$ & $38.5 \mathrm{mEq} / \mathrm{L}$ \\
\hline & Urine osmolality & $529 \mathrm{mOsm} / \mathrm{kg}$ \\
\hline
\end{tabular}

ADH: antidiuretic hormone, ALP: alkaline phosphatase, ALT: alanine aminotransferase, APTT: activated partial thromboplastin time, AST: aspartate aminotransferase, Alb: albumin, BUN: blood urea nitrogen, $\mathrm{CK}$ : creatine kinase, CK-MB: creatine kinase-MB, CRP: C-reactive protein, $\mathrm{Cl}$ : cloride, FPG: fasting plasma glucose, FT3: free triiodothyronine, FT4: free thyroxine, GGT: gamma glutamyltranspeptidase, Ht: hematocrit, K: potassium, LDH: lactate dehydroqenase, Na: sodium, PT: prothrombin time, PT-INR: prothrombin time international ratio, Plt: platelet, RBC: red blood cell, T-bil: total bilirubin, TP: total protein, TSH: thyroid stimulating hormone

blocker, and her systolic blood pressure and headache improved. On the night of the second day, headache and nausea developed again. She experienced confusion and called emergency services on the morning of the third day.

She was brought to our hospital and was examined at the neurology department. On examination, her blood pressure was $128 / 86 \mathrm{mmHg}$, her heart rate was 86 beats per minute and regular, her temperature was $36.2^{\circ} \mathrm{C}$, and oxygen saturation was $100 \%$ on room air. She did not exhibit increased perspiration, unstable circulation, or muscle rigidity. She appeared euvolemic with good skin turgor and had no signs of dehydration or circulatory overload. She experienced confusion (Glasgow Coma Scale: E3V5M4). She was able to move her extremities but was unable to perform complex movements, such as sitting up.

On admission, a laboratory analysis revealed the following findings: serum sodium, $119 \mathrm{mEq} / \mathrm{L}$; urine sodium, 187 $\mathrm{mEq} / \mathrm{L}$; serum osmotic pressure, $260 \mathrm{mOsm} / \mathrm{kg}$; urine osmotic pressure, $529 \mathrm{mOsm} / \mathrm{kg}$; blood urea nitrogen, $7.3 \mathrm{mg} /$ $\mathrm{dL}$; creatinine, $0.37 \mathrm{mg} / \mathrm{dL}$; creatinine kinase, 1,987 IU/L; creatinine kinase-MB, $33 \mathrm{U} / \mathrm{L}$; free triiodothyronine, 2.21 $\mathrm{pg} / \mathrm{mL}$; and free thyroxine, $1.380 \mathrm{ng} / \mathrm{dL}$ (Table). Lumbar puncture was not performed because she was taking warfarin and her condition improved the day after admission. Her electrocardiogram was normal and did not show any ST-T wave change. Magnetic resonance imaging revealed a hyperintense signal in the posterior part of pituitary gland on T1-weighted imaging and a hypointense signal on T2weighted imaging (Fig. 1); these findings proved that her pituitary gland was normal. Later, we found that her antidiuretic hormone (ADH) level was $1.9 \mathrm{pg} / \mathrm{mL}$ and her early morning free cortisol level was $27.8 \mu \mathrm{g} / \mathrm{dL}$.

She was administered a drip infusion of normal saline due to high levels of creatinine kinase. She was treated with sodium at $469 \mathrm{mEq}$ on the first day, $265 \mathrm{mEq}$ on the second day, and $135 \mathrm{mEq}$ on the third day. Her serum sodium levels improved the following day (Fig. 2), along with her level of consciousness. Subsequently, we diagnosed her with acute symptomatic hyponatremia caused by SIADH as a result of treatment with duloxetine, based on the criteria of the Japanese Ministry of Labor, Health and Welfare. After 1 month, she showed complete improvement and her serum sodium level was $140 \mathrm{mEq} / \mathrm{L}$.

The elevated creatinine kinase level was attributed to rhabdomyolysis caused by lying on the floor. However, this could not be verified because she lived alone and nobody observed her.

\section{Discussion}

The symptoms of hyponatremia are non-specific and range widely, including nausea, vomiting, headache, confusion, coma, seizure, encephalopathy, and central herniation. The neurologic symptoms reflect the development of cerebral edema within a rigid skull. The initial response to acute hyponatremia is an increase in the brain interstitial pressure, which leads to shunting of extracellular fluid and solutes from the interstitial space into the cerebrospinal fluid, then into the systemic circulation. This is accompanied by efflux of the major intracellular ions, such as sodium, potassium, and chloride, from neurons (3).

Hyponatremia is divided into acute and chronic phases, 


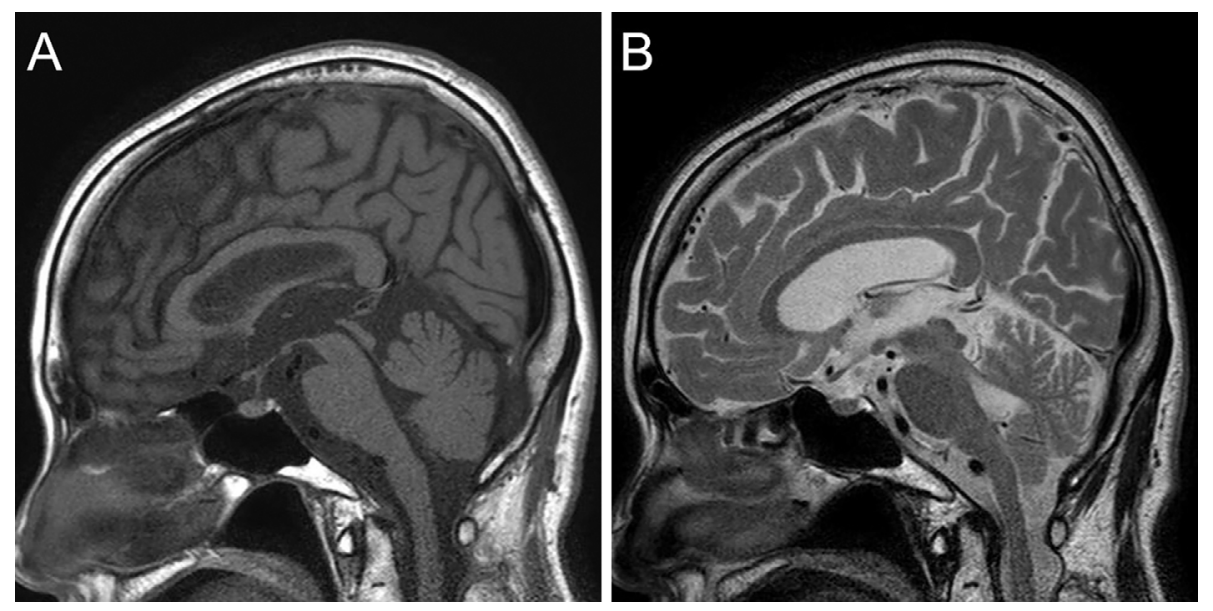

Figure 1. A) T1-weighted magnetic resonance imaging shows a hyperintense signal in the posterior pituitary gland. B) T2-weighted MRI shows a hypointense/isointense signal in the posterior pituitary gland.

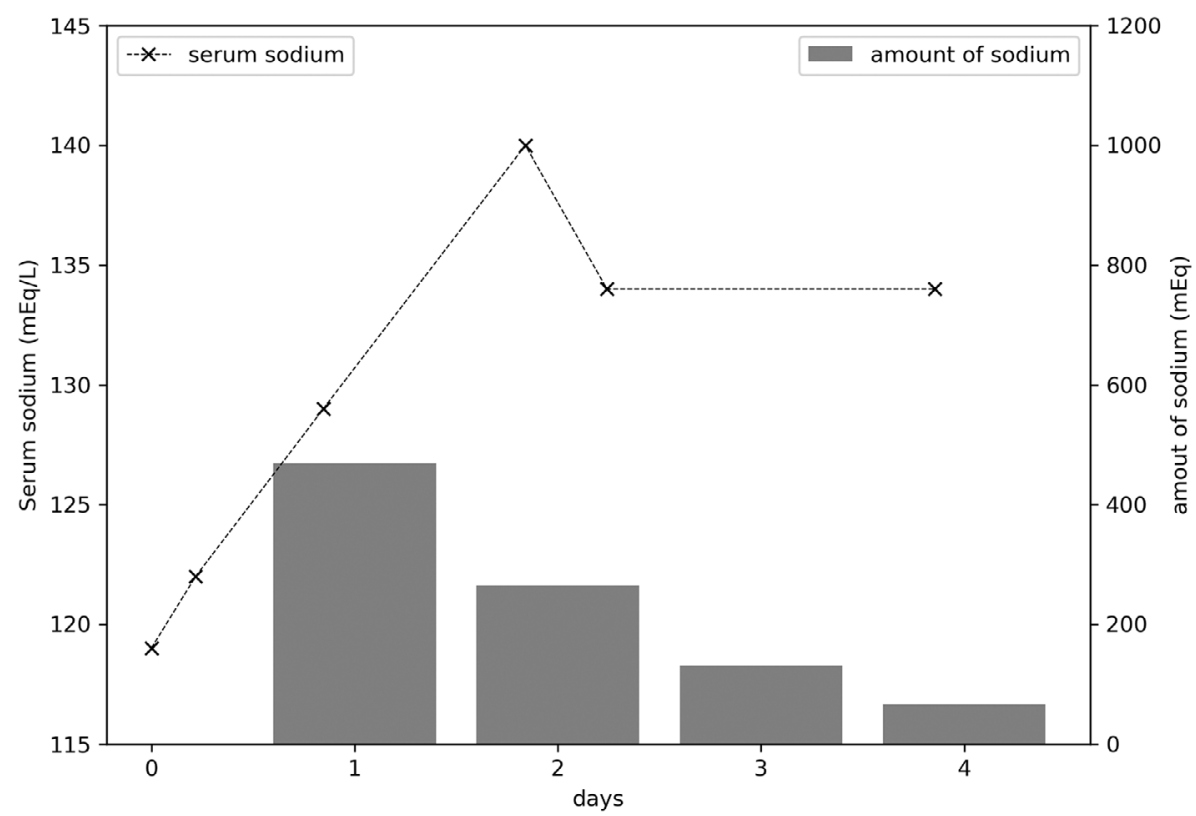

Figure 2. The time course of the serum sodium concentration and the daily sodium dose (A) (B) within 4 days after admission.

based on the differences in symptoms and treatments. Acute hyponatremia resulting in cerebral edema causes acute encephalopathy because the regulatory mechanisms that maintain the cerebral volume fail due to a rapid decrease in tonicity; thus, acute symptomatic hyponatremia represents a medical emergency. Patients with euvolemic hyponatremia due to SIADH, hypothyroidism, or secondary adrenal failure will respond to treatment of the underlying condition. Thus, it is important to identify the cause of hyponatremia and to treat it immediately (4).

Duloxetine binds to plasma proteins in human blood; Bymaster et al. reported that more than $95 \%$ of duloxetine binds to plasma proteins (5). In the presence of other drugs that bind to the plasma proteins with high affinity, the level of free duloxetine in blood increases. Moreover, the simulta- neous use of duloxetine and other drugs with high binding ratios will increase the levels of both medications, thereby increasing the risk of experiencing adverse effects.

Duloxetine is primarily metabolized by CYP1A2 and partially metabolized by CYP2D6 (6). Warfarin and zolpidem compete with duloxetine because these medicines are metabolized by CYP1A2 $(7,8)$. In addition, warfarin competes by binding to plasma proteins. The other medicines that this patient was taking were not associated with CYP1A2 or CYP2D6 metabolism and do not bind to plasma proteins. Thus, warfarin and zolpidem were the medications that likely enhanced the effect of duloxetine.

In the present case, acute symptomatic hyponatremia was considered to have been caused by SIADH due to duloxetine treatment. In elderly people, the renal function can be 
impaired (9) and ADH secretion may increase slightly (10), because the ADH secretory response to osmotic stimuli in the elderly is greater than that in younger people. Moreover, the risk of developing SIADH is high in women and individuals with a history of hyponatremia, medical comorbidities, or the intake of concomitant drugs that are known to cause hyponatremia or alter the secretion of $\mathrm{ADH}$ (11). In this case, the risk factors were female sex and the intake of other drugs; however, she had no history of hyponatremia.

SSRIs and SNRIs can induce secondary SIADH, probably through their effects on the serotonergic pathways. The chronic administration of sertraline, an SSRI, increases the levels of vasopressin and oxytocin in rats, suggesting that hyponatremia is a central phenomenon (12). In contrast, the vasopressin levels remained unchanged in a rat model of fluoxetine-induced hyponatremia (13). Drug interactions between SSRIs or SNRIs and other medications can also cause hyponatremia. SSRIs inhibit a number of cytochrome P450 isozymes, which leads to elevated serum concentrations of other medications, such as diuretics, which affect sodium homeostasis.

The risk of SIADH is relativity high within 2 weeks of starting SNRI treatment. Duloxetine has a lower risk of hyponatremia than other SSRIs or SNRIs (2). However, Siegel et al. reported a case of hyponatremic encephalopathy 4 days after starting duloxetine (14). Similarly, Amoako et al. reported a case of mild SIADH, in which the only symptom was nausea, 2 days after starting duloxetine (15). In this case, the single dose of duloxetine possibly induced SIADH because drug interactions between duloxetine and other drugs, particularly warfarin and zolpidem, enhanced the side effects of duloxetine. This implied that even a single dose of duloxetine can cause SIADH, depending on the drugs that are administered concomitantly.

To the best of our knowledge, this was the first report of hyponatremia caused by a single dose of duloxetine in a patient whose serum sodium levels were initially normal. The patient presented with headache and nausea approximately 12 hours after starting duloxetine; however, a laboratory examination showed a normal serum sodium level of 135 $\mathrm{mEq} / \mathrm{L}$. In this case, the patient's condition improved with a normal saline infusion 24 hours after admission and 60 hours after taking duloxetine. Since the half-life of duloxetine is 16 hours, the patient was observed in hospital for 12 days. This case suggests that SIADH must be considered, even if the serum sodium level is normal, particularly in symptomatic patients in whom SNRI treatment has been initiated. Headache, nausea, and high systolic blood pressure can indicate early brain edema secondary to hyponatremia, even if the serum sodium level is normal.

\section{Conclusion}

When a patient presents with headache, nausea, and high systolic blood pressure after taking even a single dose of duloxetine, clinicians must consider a diagnosis of secondary SIADH, even if the serum sodium level is within the normal limits.

The authors state that they have no Conflict of Interest (COI).

\section{References}

1. Mamdani MM, Parikh SV, Austin PC, Upshur RE. Use of antidepressants among elderly subjects: trends and contributing factors. Am J Psychiatry 157: 360-367, 2000.

2. Gandhi S, Shariff SZ, Al-Jaishi A, et al. Second-generation antidepressants and hyponatremia risk: a population-based cohort study of older adults. Am J Kidney Dis 69: 87-96, 2017.

3. Adrogué HJ, Madias NE. Hyponatremia. N Engl J Med 342: 1581-1589, 2000.

4. Sterns RH, Silver SM. Complications and management of hyponatremia. Curr Opin Nephrol Hypertens 25: 114-119, 2016.

5. Bymaster FP, Lee TC, Knadler P, Detke MJ, Iyengar S. The dual transporter inhibitor duloxetine: a review of its preclinical pharmacology, pharmacokinetic profile, and clinical results in depression. Curr Pharm Des 11: 1475-1493, 2005.

6. Knadler MP, Lobo E, Chappell J, Bergstrom R. Duloxetine: clinical pharmacokinetics and drug interactions. Clin Pharmacokinet 50: 281-294, 2011.

7. Pichard L, Gillet G, Bonfils C, Domergue J, Thenot JP, Maurel P. Oxidative metabolism of zolpidem by human liver cytochrome P450S. Drug Metab Dispos 23: 1253-1262, 1995.

8. Von Moltke LL, Greenblatt DJ, Granda BW, et al. Zolpidem metabolism in vitro: responsible cytochromes, chemical inhibitors, and in vivo correlations. Br J Clin Pharmacol 48: 89-97, 1999.

9. Lindeman RD, Van Buren, Raisz LG. Osmolar renal concentrating ability in healthy young men and hospitalized patients without renal disease. N Engl J Med 262: 1306-1309, 1960.

10. Miller M. Fluid and electrolyte homeostasis in the elderly: physiological changes of ageing and clinical consequences. Baillieres Clin Endocrinol Metab 11: 367-387, 1997.

11. Kirby D, Ames D. Hyponatraemia and selective serotonin reuptake inhibitors in elderly patients. Int $\mathrm{J}$ Geriatr Psychiatry 16: 484-493, 2001.

12. de Magalhães-Nunes AP, Badauê-Passos D, Ventura RR, et al. Sertraline, a selective serotonin reuptake inhibitor, affects thirst, salt appetite and plasma levels of oxytocin and vasopressin in rats. Exp Physiol 92: 913-922, 2007.

13. Moyses ZP, Nakandakari FK, Magaldi AJ. Fluoxetine effect on kidney water reabsorption. Nephrol Dial Transplant 23: 11731178, 2008.

14. Siegel AJ, Forte SS, Bhatti NA, Gelda SE. Drug-related hyponatremic encephalopathy: rapid clinical response averts lifethreatening acute cerebral edema. Am J Case Rep 17: 150-153, 2016.

15. Amoako AO, Brown C, Riley T. Syndrome of inappropriate antidiuretic hormone secretion: a story of duloxetine-induced hyponatraemia. BMJ Case Rep 2015: 208037, 2015.

The Internal Medicine is an Open Access journal distributed under the Creative Commons Attribution-NonCommercial-NoDerivatives 4.0 International License. To view the details of this license, please visit (https://creativecommons.org/licenses/ by-nc-nd/4.0/).

(C) 2019 The Japanese Society of Internal Medicine Intern Med 58: 1939-1942, 2019 